\title{
色・温度画像を用いたベイズ推定に基づく 人物領域抽出の基礎検討
}

\author{
Human Region Segmentation Based on Bayesian Estimation \\ Using Chroma and Thermal Video
}

\author{
澤 田 耕 司 ${ }^{\dagger}, \quad$ 高 橋 桂 $太^{\dagger}$, 正会員苗村 健 ${ }^{\dagger}$
}

Kohji Sawada $^{\dagger}$, Keita Takahashi ${ }^{\dagger}$ and Takeshi Naemura ${ }^{\dagger}$

\begin{abstract}
We have been developing a thermo-key system that segments human regions from video in real-time using thermal information. We developed a new segmentation method for this system based on Bayesian estimation, which uses both chroma and thermal information integratively. Segmentation algorithms were previously based on a simple threshold processing of thermal images, which often results in wrong segmentation of objects/environments whose temperatures are close to body temperature. Trained with only a few sets of chroma and thermal images, our algorithm can extract human regions from video with much higher accuracy compared to previous algorithms.
\end{abstract}

キーワード: Thermo-key, 人物領域抽出, ベイズ推定, 統計的手法

\section{1. まえがき}

画像中からの人物領域抽出は，人の領域に選択的にフィ ルタをかけたり，人物を切り出して別の背景に重畳するな ど，豊かな映像効果を実現する上で重要な基盤技術の一つ である。そのため，これらは放送・通信やエンタテインメ ントアプリケーション，メディアアートなど様々な分野で 利用されている。

具体的な抽出手法としては，まず chroma-key が挙げら れる，放送業界で長く利用されている千法であるが，単一 色の背景が必要であるため, 専用のスタジオでしか利用で きない.より一般的な背景を許容する手法としては背景差 分 ${ }^{1)}$ がある. 微小な背景変化や照明変化に対応する方法が 提案されていものの, 背景に大域的な変化が起こらないと いう条件が必要である. 動きの情報をもとに抽出を行う手 法として, オプティカルフロー ${ }^{2)}$ が挙げられる. カメラの パン・チルトが施された場合でも, 動物体の抽出が可能であ る反面, 計算コストが高いという欠点がある. 簡易的な動 き情報を用い, コントラストを考慮したエネルギー最適化 に基づいて抽出を行う手法 ${ }^{3)}$ も提案されている. 高精度な

2007 年 10 月 31 日受付, 2007 年 11 月 30 日再受付, 2007 年 12 月 4 日 採録

†東京大学大学院 情報理工学系研究科

(₹ 113-8656 東京都文京区本郷 7-3-1, TEL 03-5841-6761)

$\dagger$ Graduate School of Information Science and Technology, The University of Tokyo

(7-3-1 Hongo, Bunkyo-ku, Tokyo, 113-8656 Japan)
抽出を実時間で行うことが可能とされているが，この方法 ではカメラが固定されていることが前提となっている。一 方で, 単眼のビデオ画像以外の情報として, 距離情報に基 づく手法がある。ステレオ視を利用した手法 ${ }^{4)}$ では，視 差情報を得るために画像間のマッチングを取る必要があり， 計算コストが高い. Axi-Vision カメラ ${ }^{5)}$ のような特殊な 装置によって得られる距離画像を用いる方法もある。

一方, 我々は温度情報をキーにした人物領域抽出手法で ある thermo-key 方式の研究開発を行ってきた ${ }^{6) 7)}$.この システムは, 図 1 に示すように光軸を一致させたカラーカ メラと温度カメラで構成されており, 被写体の色画像と温 度画像を同時に撮影することができる。この方式の特徴は, 人物・背景の色分布や背景変化に依存しないロバストな人物 領域抽出が可能なことである。これまで我々は thermo-key を用いた抽出手法として, 温度画像に対する単純な閾值処 理（人物の体温に近い温度を持つ画素を人物領域と判定） を基本とした処理を採用してきた。このため，例えば肌の 露出している顔面に自動的にモザイクを施すような処理で は比較的良好な結果が得られてきたが, 温度の低い衣服も 含めた抽出には難があった。 これに対し, 温度画像に対す る背景差分をとる方法 (熱背景差分) を提案したが, 撮像 系の移動やパン・チルトができないという欠点があった。ま

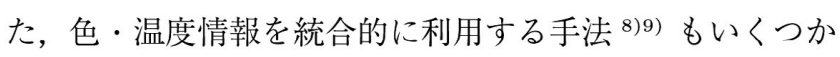
提案してきたが，いずれも限定された状況への対応策に止 まっていた。

本稿では，これらの問題を改善するため，色と温度の統 


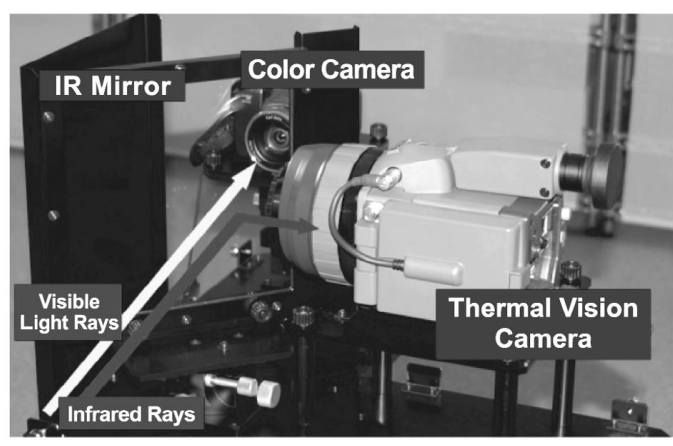

図 1 thermo-key の構成 Thermo-key system.

計的な分布を考慮した新しい人物領域抽出手法を提案する. 提案手法はベイズ推定の原理に基づいており，各画素が人 物領域である確率を, 単純な仮定に基づく事前確率と, 統 計的デー夕に基づく尤度の積によって推定する。この手法 では，人間の体温に近い物体が配置された空間を対象とす る場合や，撮像系の移動，パン・チルトを許谷する場合で も人物領域の抽出が可能である。実験では，あらかじめ撮 影した 240 フレームのビデオシーケンスのうち 3 フレー ムのみから尤度を学習し, ビデオシーケンス全体に対して 高い精度で人物領域を抽出できることを示した．現段階で 実装した手法は単純なものではあるが, 統計的な人物領域 抽出のキーとして, 色と温度の両方を用いることの優位性 を明らかにする点では充分な結果が得られた。

\section{2. ベイズ推定に基づく人物領域抽出}

システムへの入力は，光軸を一致させた状態で撮影され た色画像と温度画像の組である（図 2 ）。

時刻 $t$ に撮影された色画像を $C^{t}$, 温度画像を $\boldsymbol{T}^{t}$ とす る.これらの画像に打いて $i$ 番目に位置する画素の值を $C_{i}^{t}, T_{i}^{t}$ とすると, この画素がラベル $x$ に属する事後確率 $P\left(x \mid C_{i}^{t}, T_{i}^{t}\right)$ は, ベイズの定理により次のように書ける.

$$
P\left(x \mid C_{i}^{t}, T_{i}^{t}\right)=\frac{P\left(C_{i}^{t}, T_{i}^{t} \mid x\right) P(x)}{P\left(C_{i}^{t}, T_{i}^{t}\right)}
$$

ここで $x \in\{h, b\}$ であり, $h$ は人物領域を, $b$ は背景領域を 表す. ラベル $h, b$ について, $P\left(h \mid C_{i}^{t}, T_{i}^{t}\right)+P\left(b \mid C_{i}^{t}, T_{i}^{t}\right)=$ 1 であることから，画素が人物領域に属する事後確率は

$$
P\left(h \mid C_{i}^{t}, T_{i}^{t}\right)=\frac{P\left(C_{i}^{t}, T_{i}^{t} \mid x=h\right) P(x=h)}{\sum_{x \in\{h, b\}} P\left(C_{i}^{t}, T_{i}^{t} \mid x\right) P(x)}
$$

と書くことができる。したがって， $P\left(h \mid C_{i}^{t}, T_{i}^{t}\right)$ を求める には, 尤度 $P\left(C_{i}^{t}, T_{i}^{t} \mid x\right)$ と事前確率 $P(x)$ が必要である.

最終的な抽出結果は, 入力画像の各画素に対して求めら れた $P\left(h \mid C_{i}^{t}, T_{i}^{t}\right)$ を配列した画像として与えられる。この 画像は, 各画素が人物領域に含まれる確からしさを表すも のであり，画像全体を $\alpha^{t}$ と書く

\section{1 尤度}

尤度は学習デー夕から求める. 撮影環境の色・温度の分

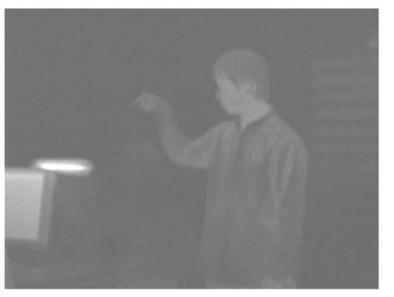

(a) 温度画像

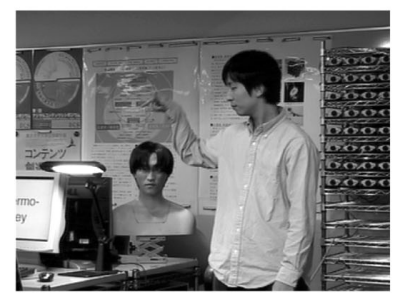

(b) 色画像
図 2 入力画像の例 (Frame No.107) A pair of input images.

布を正解デー夕を与えて事前に学習し，人間・背景それぞ れについてヒストグラムを作成しておく。このヒストグラ ムを総面積が 1 になるように正規化することで，尤度を表 す確率密度関数を求める.

色 $C$ と温度 $T$ に対するラベル $x$ のヒストグラムを $H_{x}(C, T)$ とし, ヒストグラムの総面積を $S_{x}$ とすると, 尤 度は次のように書くことができる。

$$
P(C, T \mid x)=\frac{H_{x}(C, T)}{S_{x}}
$$

ここで, $C$ は $(R, G, B)$ の 3 值を含むので, ヒストグラ 厶 $H_{x}(C, T)$ は $(R, G, B, T)$ の 4 值による 4 次元空問上 で作成されることになる。

\section{2 事前確率}

事前確率 $P(x)$ はシンボル $x$ の出現確率であり, 何らか の仮定に基づいて任意に定める必要がある．本稿では以下 の 2 通りの方法を考える.

（1）面積比を用いる場合

人物領域が画面中に出現する位置について全く仮定を置 かない場合，その出現確率は，人物領域が画面に占める割 合であると解釈することができる。ここでは，学習により 作成されたヒストグラムに扔ける，人物領域と背景領域の 面積の比を用いる。すなわち，人間・背景それぞれのヒス トグラムの総面積 $S_{h}, S_{b}$ を用いて,

$$
P(x)=\frac{S_{x}}{S_{h}+S_{b}}
$$

とする

（2）時系列の相関を用いる場合

ある画素 $i$ の時刻 $t$ に扔ける事後確率 $P\left(x \mid C_{i}^{t}, T_{i}^{t}\right)$ は, 同じ画素の時刻 $t-1$ における事後確率 $P\left(x \mid C_{i}^{t-1}, T_{i}^{t-1}\right)$ と強い相関があると考えられる。そこで，時刻 $t-1$ にお ける結果画像 $\boldsymbol{\alpha}^{t-1}$ をもとに，何らかの方法によって時刻 $t$ に㧍ける事前確率マップ $\boldsymbol{M}^{t}$ を推定し，事前確率を以下 のように定める.

$$
P_{i}^{t}(x)= \begin{cases}M_{i}^{t} & x=h \\ 1-M_{i}^{t} & x=b\end{cases}
$$

このとき問題となるのは, $\alpha^{t-1}$ から $M^{t}$ をいかに推定 


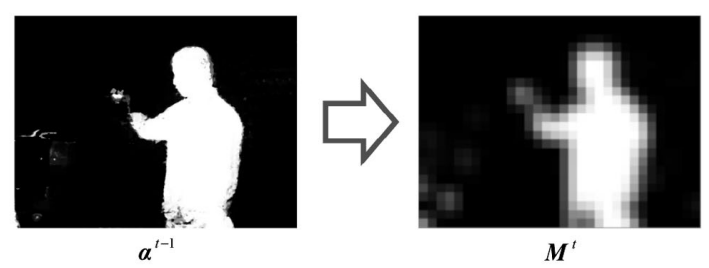

図 3 事前確率マップの作成 Prior map.

するかということである．特に，連続するフレーム間で人 物の移動量が大きい部分において, 精度のよい推定は困難 となる. 本稿では, $\alpha^{t-1}$ をいったん低解像度化して処理 することで，大きな移動量にも対応できると考え，以下の ような手順を用いた.

$$
\boldsymbol{M}^{\boldsymbol{t}}=G_{k_{1}}\left(\operatorname{Resize}_{s_{1}}\left(G_{k_{2}}\left(\operatorname{Resize}_{s_{2}}\left(\boldsymbol{\alpha}^{\boldsymbol{t}-\mathbf{1}}\right)\right)\right)\right)
$$

ここで, $G$ はガウシアンフィルタによる平滑化を, Resize は画像の拡縮処理を表す。ガウシアンフィルタのカーネル サイズ $k_{1}, k_{2}$ と拡縮のスケール $s_{1}, s_{2}$ は実験的に定め ることにし，ここでは $k_{1}=7 \times 7, k_{2}=3 \times 3, s_{1}=20$, $s_{2}=1 / 20$ とした. 拡縮処理の補間方法としていくつかの 方法を試行錯䛊した結果, 縮小時には双線形補間を, 拡大時 には最近傍補間を採用した.この手順による処理絬果の例 を図 3 に示す．縮小拡大に平滑化を加えることで，人物領 域および背景領域の時間的連続性だけではなく, 空間的な 連続性も同時に考慮したアルゴリズムとなっている。なお, 推定の精度をさらに向上させるためには，ランダムウォー クモデルやオプティカルフローなどに基づく方法も考えら れ, 今後の検討の課題としたい.

\section{3. 実 験}

本実験では，素材として一連のビデオシーケンス（240 フレーム, $15 \mathrm{fps}$ ) を撮影した.このビデオは色画像のビ デオと温度画像のビデオの組で成り立っており, 色画像の 解像度は $640 \times 480$, 色深度は 24 bit フルカラーである. 温度画像の解像度は $320 \times 240$, 深度は 8 bit グレースケー ルであり，これを色画像に合わせて $640 \times 480$ に引き伸ば して使用している。このビデオでは背景にマネキンやポス ターなどが配置してあるため, 色によるキーイングは難し い. また, 蛍光灯やモ二夕, 右奥の実験装置など, 人の体 温に近い温度を持つ物体が存在しており, 従来の温度画像 に対する閾值処理では抽出が困難である.さらに, 途中で カメラがパンしている（No.70〜 190）ことで, 背景差分 が利用できない素材であるといえる。

2.1 で述べたように, 尤度は学習によって作成したヒス トグラムから求める。本実験では, 実験用素材のビデオの 中から 図 4 に示す三つのフレーム（No.1, 133, 198）を 選び，これらを用いて学習を行った. 各フレームについて， 筆者が人物・背景に対応する正解領域を与え, そこに含ま れる画素の值 $(C, T)$ を集計することで, 人物のヒストグ
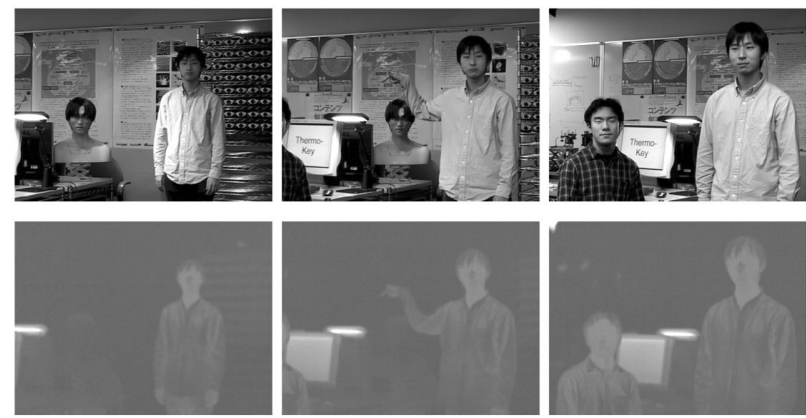

図 4 学習に用いる 3 フレーム（No.1, 133, 198） 3 frames for learning.

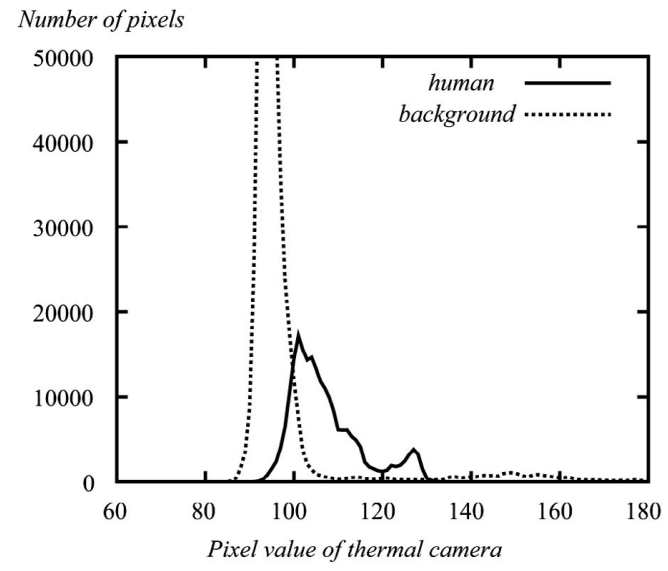

図 5 温度のヒストグラム Thermal histogram.

ラム $H_{h}(C, T)$ と背景のヒストグラム $H_{b}(C, T)$ をそれぞ れ作成した。その際，色 $(R, G, B)$ はそれぞれ 4 bit に，温 度 $T$ は 6 bit に落とし，合わせて 18bit の空間を持つヒス トグラムとした.ここで参考のため, 温度 $T$ のみを集計し たヒストグラム (8bit) を図 5 に示す. 人物領域の分布と 背景領域の分布が大きく重複しており，従来のような䦨值 処理によって人物領域を抽出するのは困難であることがわ かる.

入力ビデオのうち, 図 2 に相当する画像の組 (No.107) に 対する抽出結果を 図 6 に示す.これらの結果画像の輝度值 は，その画素が人物領域に含まれる確からしさを表す。図 6 のうち，(a)(b) は比較のため画像・温度画像のみを用いて抽 出を行った結果であり (color only, thermo only), (c)(d) は提案手法による結果である（color + thermo, color + thermo with temporal). (a)(b) では，尤度をそれぞれ $P(C \mid x), P(T \mid x)$ として, 色または温度の值のみを集計し たヒストグラムを用いた。 ここで，色ヒストグラムの bit 数については, RGB 各チャネルを 4bit および 6bit とし た場合を比較し，より精度の高かった 6 bit を用いた。これ は 3 チャネル合わせて 18 bit であり，提案手法に用いたヒ ストグラムと平均密度が等しくなっている．温度について も 6bit および 8bit の場合を比較し，精度の高かった 8bit を用いた。 


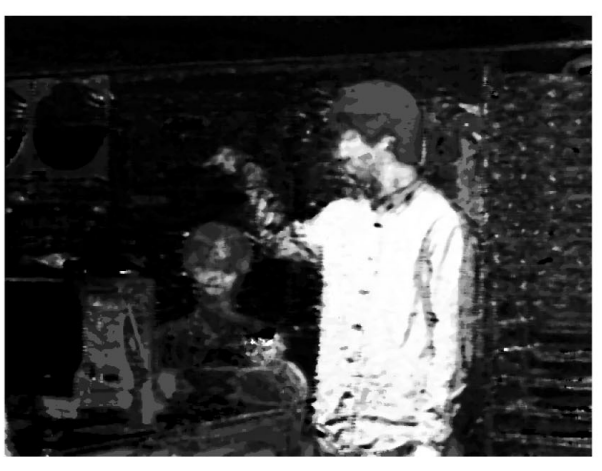

(a) color only

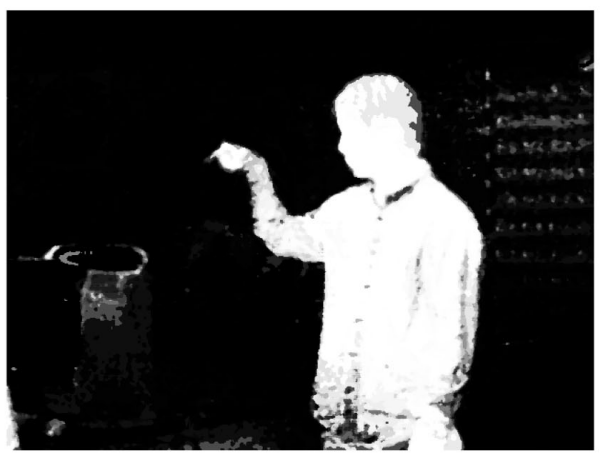

(c) color + thermo

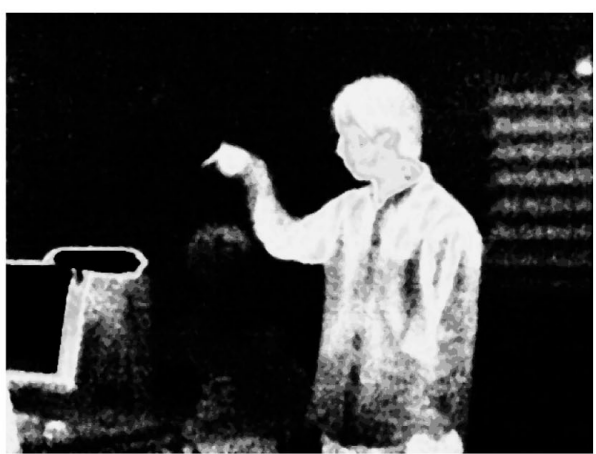

(b) thermo only

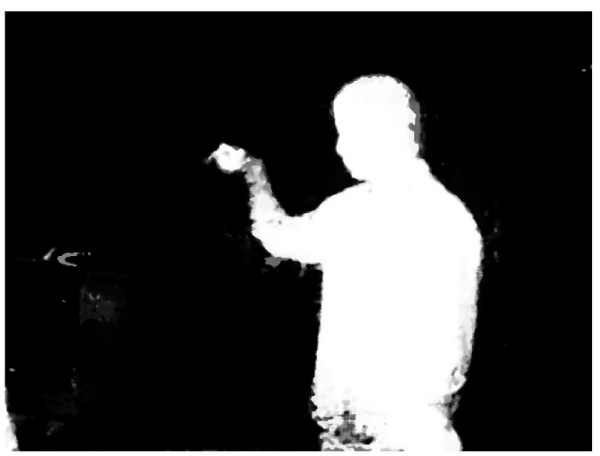

(d) color + thermo with temporal

図 6 抽出結果 (No.107)

Result of segmentation.

図 6(a) では色分布の情報のみを用いているため，肌や 髮，衣服に色の近い領域で誤りが目立つ。また図 6(b)で は，体温に温度が近いモニ夕や実験装置のほか，衣服のう ち温度が低い領域などにおいて誤った結果が出ている。こ れは, 温度画像のみによって抽出を行っているという点で, 従来手法 ${ }^{677)}$ に近い結果であるといえる。これらに比べ, 提案手法による結果（図 6(c) (d) ) では, 背景の誤検出率 が抑えられ，抽出精度が高まっていることがわかる. (c) で は, 尤度として色と温度を合わせた $P(C, T \mid x)$ を用い, 事 前確率は面積比から求めている. (d) では, 事前確率マッ プを用いた時空間推定によって事前確率を計算することで, さらに精度が向上している。

図 6(d) の方法による抽出結果を元に, 色画像から人物 領域を切り出した結果を図 7 に示す。一部背景が残ってし まっているものの, 従来于法を上回る精度で人物が切り出 されている。

最後に, 図 8 に本手法による抽出の精度を定量的に計 測した結果を示す.ここでは, 入力ビデオ 240 フレームの うち 40 フレームを適当に選び，それらを入力として，図 6 に示した四つの方法を用いて人物領域を抽出したときの $\mathrm{F}$ 值（式 10）を求めた。評価には連続する10 フレームを 4 区間取って用い（No. $22 \sim 31,102 \sim 111,162 \sim 171$, 202 ～211），学習に用いたフレームが入らないようにし
た．各フレームに対する $\mathrm{F}$ 值の算出は以下のように行った。 まず，人の手で切り抜いた正解画像 $\boldsymbol{R}$ (2 值) を用意して おく.これを抽出結果画像 $\boldsymbol{\alpha}$ と比較することによって適合 率と再現率を計算するが， $\boldsymbol{\alpha}$ は確率を表す多值画像 (8 bit グレースケール) であるから，単純に論理積をとることが できない. そこで，これら $\boldsymbol{\alpha}$ と $\boldsymbol{R}$ の各画素について積を とった画像を $\boldsymbol{P}$ とする。

$$
P_{i}=\alpha_{i} \times R_{i}
$$

これを用いて，抽出結果の適合率 Precision と再現率 Recall を次のように定めた。

$$
\begin{aligned}
\text { Precision } & =\sum_{i} P_{i} / \sum_{i} \alpha_{i} \\
\text { Recall } & =\sum_{i} P_{i} / \sum_{i} R_{i}
\end{aligned}
$$

これら二つの值から， $\mathrm{F}$ 值は次の式で与えられる.

$$
\mathrm{F}=\frac{2 \times \text { Precision } \times \text { Recall }}{\text { Precision }+ \text { Recall }}
$$

図 8 の結果を見ると, 色・温度情報をそれぞれ単独で 用いる (color only, thermo only) より, 統合的に用いた (color + thermo）方が高い精度が得られている。また， 事前確率の計算に時空間推定を用いる (color + thermo with temporal）ことで, さらに精度が向上していること 

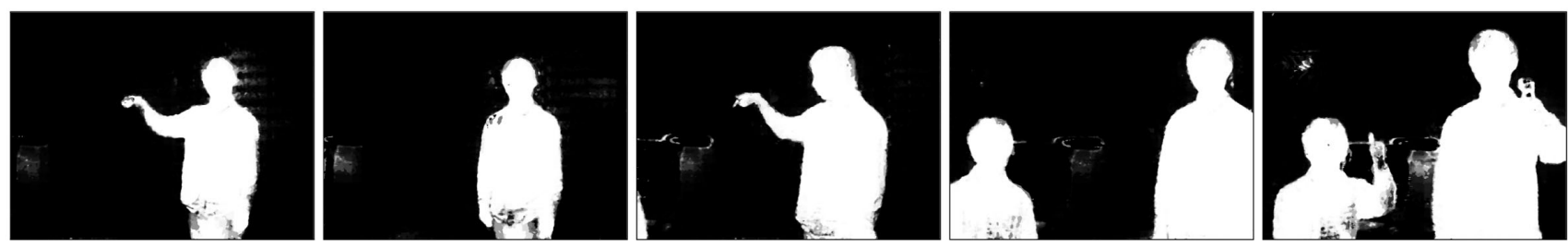

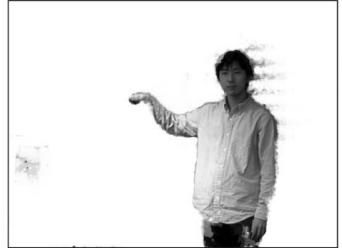

No.26

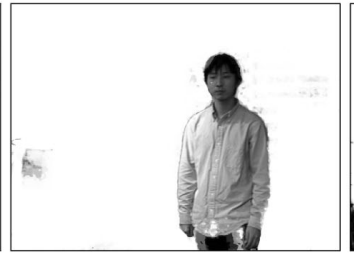

No. 81

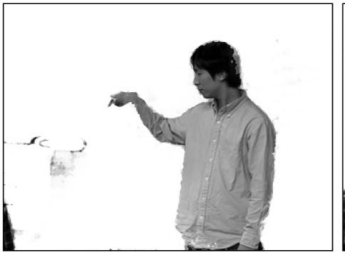

No.111

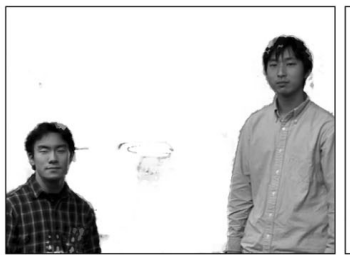

No. 170

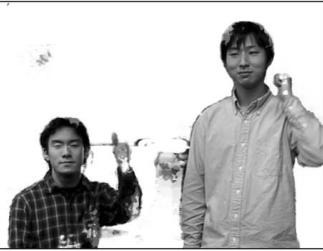

No.210

図 7 人物の切り出し結果 Cutout of human region.

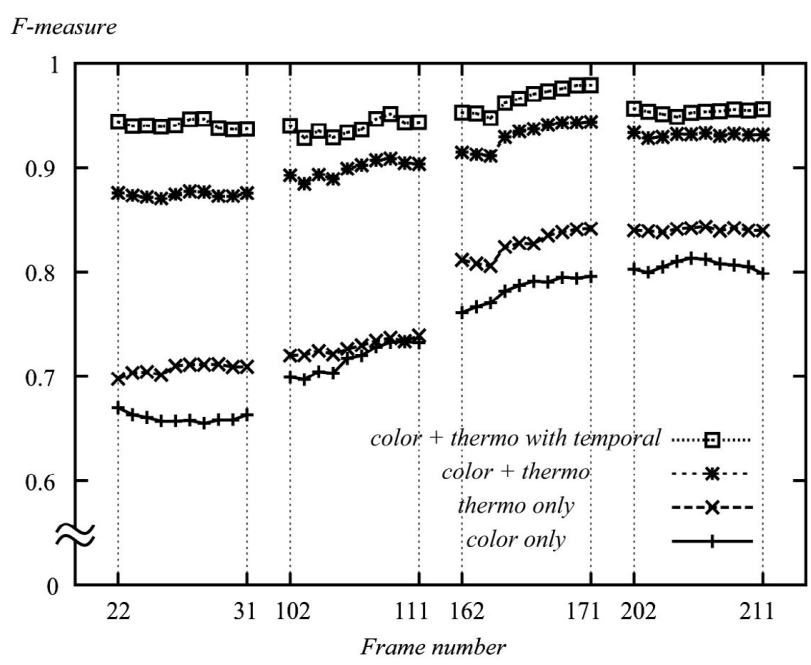

図 8 精度評価

Accuracy evaluation.

がわかる。

\section{4. むすび}

本稿では，thermo-key システムを利用した人物領域抽 出として, 色と温度両方の統計的分布情報を用いたべイズ 推定に基づく手法を提案した。この手法により，従来の温 度情報のみを用いた抽出に比べ，精度を大きく向上させる ことができた。

本稿で報告した手法は, 人物領域抽出の最新の研究と比 較するとアルゴリズムの面では単純である.しかし，単純な 于法でありながら比較的良好な精度を得られたことで，人 物領域抽出に温度情報を取り入れることの有效性を示すこ とができたといえよう。今後は，動きの情報を用いたり ${ }^{2)}$ ，

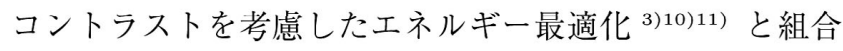
せることで, 抽出精度のさらなる向上が期待できる. 現在, グラフカットによる領域分割との組合せについて，基礎的 な検討を始めている ${ }^{12)}$.

別の課題として, リアルタイム処理への応用が挙げられ
る。本稿では撮影済みのビデオに対するポスト処理として の実装を述べたが，学習方法を工夫することで，実時間で の運用も可能になると考えている。また，現段階の実装では 並列処理等の最適化を全く行っていないが，1 フレーム当た りの処理時間は Core 2 Duo $2.1 \mathrm{GHz}$ の計算機上で $170 \mathrm{~ms}$ であり，処理速度の観点からも実時間化は容易であると考 えられる。

最後に，本研究を進めるに際し，熱心な議論をしていた だいた東京大学 原島博教授, 西貝吉晃氏, 天野翔氏に感謝 いたします.

\section{〔文献〕}

1) M. Piccardi : "Background subtraction techniques: a review", Proc. of IEEE SMC 2004, 4, pp.3099 - 3104 (2004)

2) J. L. Barron, D. J. Fleet, and S. S. Beauchemin : "Performance of optical flow techniques", Int. J. Computer Vision, 12, 1, pp.43 77 (1994)

3) A. Criminisi, G. Cross, A. Blake and V. Kolmogorov : "Bilayer Segmentation of Live Video", Proc. of IEEE CVPR 2006, 1, pp.53 $-60(2006)$

4) V. Kolmogorov, A. Criminisi, A. Blake, G. Cross, and C. Rother : "Bi-layer segmentation of binocular stereo video", Proc. of IEEE CVPR 2005, 2, pp.1186 - 1193 (2005)

5）河北 真宏, 飯塚 啓吾, 飯野 芳己, 㐘池 宏, 藤掛 英夫, 會出 出人：“実 時間距離検出 3 次元テレビカメラ (Axi-Vision カメラ)", 信学論 D-II, 87, 6, pp. $1267-1278$ (2004)

6）川原圭博, 苗村 健, 原島 博 : “サーマルビジョンカメラを用いた透過型 ビデオアバタ”, 信学総大, A-16-22 (2000).

7）西貝 吉晃, 飯田 誠, 苗村 健：“Thermosaic: 温度情報を利用した自動 モザイク処理”, 映情学誌, 59, 3, pp.422-426 (2005)

8）安田 和隆, 飯田 誠, 苗村 健：“温度情報と色情報を併用した実画像か らの人物領域抽出”, 信学技報 PRMU2003-175, 103, 515, pp.25-30 (2003)

9）塚本 敏弘, 西具 吉晃, 苗村 健 : “エッジ保存平滑化フィルタを用いた Thermo-key の抽出精度改善”, 信学技報 PRMU2004-161, 104, 572, pp. $43-48$ (2005)

10) Y. Boykov and M. P. Jollie: "Interactive graph cuts for optimal boundary and region segmentation of objects in N-D images", Proc. of ICCV 2001, 1, pp.105 - 112 (2001)

11) J. Wang and M. F. Cohen: "An iterative optimization approach for unified image segmentation and matting", Proc. of ICCV 2005, 2, pp.936 - 943 (2005)

12）ファンヴェトクォク, 高橋桂太, 苗村健 : “グラフカットを用いた色・温 度画像からの人物領域抽出の基礎検討”, IMPS 2007, I2-01 (2007) 


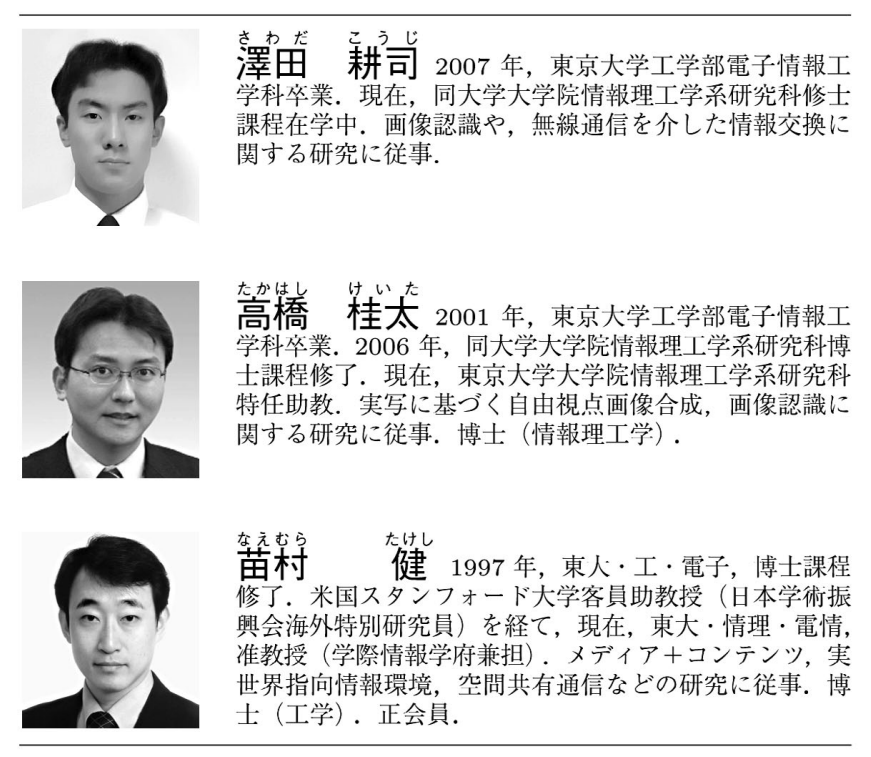

